OPEN ACCESS

Edited by:

Antonio Vitale,

University of Siena, Italy

Reviewed by:

Sinisa Savic,

University of Leeds, United Kingdom

Adriana Almeida De Jesus,

National Institutes of Health $(\mathrm{NIH})$,

United States

*Correspondence:

Sandro F. Perazzio

sperazzio@yahoo.com.br

Specialty section: This article was submitted to Autoimmune and

Autoinflammatory Disorders,

a section of the journal

Frontiers in Immunology

Received: 23 July 2020

Accepted: 28 September 2020

Published: 20 October 2020

Citation:

Perazzio SF, Andrade LEC and de Souza AWS (2020) Understanding

Behçet's Disease in the Context of

Innate Immunity Activation.

Front. Immunol. 11:586558.

doi: 10.3389/fimmu.2020.586558

\section{Understanding Behçet's Disease in the Context of Innate Immunity Activation}

\author{
Sandro F. Perazzio *, Luis E. C. Andrade ${ }^{1}$ and Alexandre W. S. de Souza \\ Division of Rheumatology, Universidade Federal de São Paulo, São Paulo, Brazil
}

Behçet's disease $(\mathrm{BD})$ is a heterogeneous condition consisting of idiopathic systemic vasculitis affecting large and small blood vessels of different types (i.e., arteries, veins, or capillaries). The disease frequently occurs in young adults without gender predilection, differently from several other autoimmune conditions. This challenging illness has recently been proposed by some authors as an example of complex autoinflammatory syndrome. Although much remains unanswered about BD pathogenesis, recent understanding of some aspects of innate immunity have clarified a few issues (and raised others). HLA- $B^{\star} 51$ represents the strongest genetic risk factor for $B D$ to date, albeit several other HLAindependent loci have also been associated with the disease. The consistent hyperreactivity against Streptococcus sanguinis antigens and alterations in oral and gut microbioma suggests that infectious agents may play an important role. Moreover, functional abnormalities of pattern recognition receptors, especially Toll-like receptors in monocytes, have been demonstrated in patients with $\mathrm{BD}$ and can be associated with the development of the disease. Neutrophil hyperactivity is one of the most consistent findings in $\mathrm{BD}$ pathogenesis, as demonstrated by exacerbated constitutive oxidative burst, chemotaxis and NET formation. However, some studies suggest that the phagocyteactivated status in $\mathrm{BD}$ is not primary to the disease itself, but rather restricted to a fraction of patients with severe disease activity, and probably secondary to activating soluble factors carried by serum/plasma from BD patients. Herein we review the state of the art on $\mathrm{BD}$ etiopathogenesis with special emphasis on the participation of the innate immune system

Keywords: Behçet's disease, innate immunity, phagocytes, neutrophil hyperactivity, alarmin, Streptococcus sanguinis

\section{INTRODUCTION}

Behçet's disease (BD) is an idiopathic systemic vasculitis affecting large and small blood vessels. It was initially described as recurrent oral and genital ulcers associated with anterior uveitis with hypopyon by Hulusi Behçet (1) and Benediktos Adamantiades (2) in the 1930s. Progressively, however, a variety of musculoskeletal, neurological, gastrointestinal and vascular manifestations was associated to the syndrome.

The epidemiology of $\mathrm{BD}$ exhibits an interesting geographic distribution throughout the ancient "Silk route", with higher prevalence in Turkey, Iran and Japan. The disease frequently occurs in 
young adults (mean age: $25-30$ years old) (3). The lack of gender predominance is one of the arguments favoring the nonautoimmune nature of $\mathrm{BD}$ pathogenesis. This challenging illness received special attention in the last years, culminating with novel insights on the possible autoinflammatory etiopathogenesis of the disease, which encouraged some authors to consider $\mathrm{BD}$ as an example of complex autoinflammatory syndrome (4). Much remains unanswered in $\mathrm{BD}$ pathogenesis, as recent progress in the understanding of some aspects of the innate immunity has raised unforeseen questions. Herein we review the state of the art on $\mathrm{BD}$ etiopathogenesis with special emphasis on the participation of innate immunity activation.

\section{THE IMMUNOGENETIC BASIS OF BEHÇET'S DISEASE}

\section{Histocompatibility Leucocyte Antigen}

Histocompatibility leucocyte antigen (HLA)-B ${ }^{\star} 51$ represents the strongest genetic risk factor for $\mathrm{BD}$ to date. It was initially reported in the Japanese (5) and reproduced among several other ethnic groups (6). A meta-analysis reported an overall odds ratio of 5.78 (95\% CI=5.00-6.67) for $H L A-B^{\star} 51$ carriers to develop $\mathrm{BD}$, independently of the ethnicity (6). Similar results were confirmed in two different genome-wide association studies (GWAS) in Japanese (7) and Turkish BD patients (8). However, recently other loci have been demonstrated to increase the risk of $\mathrm{BD}$ as well. Kuranov et al. (9) studied HLA-B ${ }^{\star 51-n e g a t i v e ~}$ patients and showed a significant association of $\mathrm{BD}$ and HLABw4-80I, an epitope present on B locus-derived proteins, characterized by the presence of an isoleucine at amino-acid position 80 in the $\alpha 1$ helix of the HLA-B ${ }^{\star} 04$. Additionally, these authors found an association with HLA-A 26 independent from $\operatorname{HLA}^{\star}{ }^{\star} 51$, which was confirmed in other studies $(8,10)$. In addition, Hughes et al. (10) demonstrated that HLA- $A^{\star} 03, B^{\star} 15$, $\mathrm{B}^{\star} 27, \mathrm{~B}^{\star} 49$ and $\mathrm{B}^{\star} 57$ also contribute to $\mathrm{BD}$ risk independently, although this has not been replicated to the moment. Another study identified additional independent risk factors for $\mathrm{BD}$ located at HLAB/MICA and at the region between HLA-F and HLA-A (11).

\section{Other Genetic Risk Factors}

GWAS in BD patients identified extra-HLA genetic risk factors. By analyzing 311,459 SNPs in 1,215 BD patients and 1,278 controls, Remmers et al. (8) identified two novel susceptible loci for BD: IL23R-IL12RB2 and IL10 (allele rs1518111 A, associated with low mRNA and protein expression). Recently, association between IL10 polymorphisms and BD was also demonstrated in Chinese patients (12). These data emphasize the possible role of IL-10 in $\mathrm{BD}$ pathogenesis and raise the question of possible participation of adaptive immunity, especially Th17 and Treg cells, in BD (13).

Copy number variation (CNV) of Complement component C4 genes was investigated in $\mathrm{BD}$. In contrast to systemic lupus erythematosus (14), there is an increased frequency of more than
2 copies of the $C 4 A$ gene in $\mathrm{BD}$ patients and this represents a risk factor independent from $H L A-B^{\star} 51$ (15). Moreover, the authors also demonstrated that $\mathrm{BD}$ patients with high $C 4 A$ copy number had increased production of IL-6, an important mediator of the innate immunity acting as an acute phase reactant.

Another interesting observation is the presence of a specific chromosomal abnormality in a number of patients with BD: trisomy of chromosome $8(16,17)$. Considered a risk factor for myeloid leukemia (18) and myelodysplastic syndrome (19), appearing in $5-10 \%$ of patients, trisomy 8 also seems to play a role in $\mathrm{BD}$. As shown in a recent study, its frequency was reported as high as $86 \%$ in patients with concurrent $\mathrm{BD}$ and myelodysplastic syndrome (20). Apparently, these cases present frequently with prominent gastrointestinal involvement and no geographical preference (21). Interestingly, chromosome 8 harbors some pivotal genes related to innate immunity modulation and NF- $\kappa B$ pathway activation, such as IKBKB.

\section{ALARMINS AND MICROORGANISMS}

Alarmins are a group of proteins with the ability of initiating the innate immune response after quick release following cell necrosis. Alarmins activate pattern recognition receptors (PRR), such as Toll-like receptors (TLR), and are essential to restore homeostasis after tissue damage. In fact, alarmins are considered a subtype of DAMP (damage-associated molecular patterns), which consist of stereotyped molecular patterns shared by molecules originated after exposure to physical or chemical agents capable of inducing tissue damage (e.g., radiation, heat and cold, among others).

The High Mobility Group Box 1 (HMGB1) is probably the most studied alarmin in systemic autoimmune rheumatic diseases (22-26). Ahn et al. (27) demonstrated that HMGB1 serum levels are increased in BD patients, especially those with gastrointestinal involvement. Conversely, our group found higher HMGB1 levels in BD patients compared to controls, regardless of disease activity, disease manifestations or therapy with prednisone and azathioprine (28). Han et al. (29) reported increased serum levels of alarmin S100A12 in BD, independently of disease activity, although at higher magnitude in active phase. Accordingly, S100A12 serum levels decreased after the treatment and the protein expression was increased in skin biopsies of active erythema nodosum lesions from BD patients.

There is also some evidence regarding the role of microorganisms on BD. The hyper-reactivity against Streptococcus sanguinis antigens and the homology and potential cross-reactivity of some of its proteins with human heat-shock proteins (HSP) (30), as exemplified by the activation of $\mathrm{T} \gamma \delta^{+}$cells by the pathogen and HSP $60 / 65 \mathrm{kDa}(31)$, suggest this infectious agent might play an important role in BD pathogenesis (32). Herpes simplex virus 1 (HSV-1), Staphylococcus aureus, Mycobacterium tuberculosis and some Prevotella species have also been identified as potential candidates (33). HSV-1 RNA and DNA were found in increased frequency in cells from $\mathrm{BD}$ patients $(34,35)$. Moreover, mycobacterial HSP peptides stimulate $\gamma \delta^{+}$T cells from BD 
patients, which, in turn, are increased in peripheral blood and mucosal lesions (36). Despite these intriguing set of data, a direct causal relationship between infectious agents and $\mathrm{BD}$, as well as the precise role of $\gamma \delta^{+} \mathrm{T}$ cells on the disease pathogenesis, remain unclear.

\section{TOLL-LIKE RECEPTORS AND OTHER PRR}

Evidence of increased serum levels of alarmins and hyperactivity against some microorganisms turns plausible the hypothesis that PRR participate in $\mathrm{BD}$ pathogenesis. Indeed, functional abnormalities of PRR and their activation cascades have been identified in previous studies and can be associated with BD development. Yavuz et al. (37) demonstrated that TLR6 expression is significantly increased in granulocytes from BD patients after stimulus with Streptococcus sanguinis or HSP-60 compared to rheumatoid arthritis patients and healthy controls. Interestingly, monocytes from BD patients presented lower TLR2 expression after the same stimuli. Of interest, Neves et al. (38) and Do et al. (39) showed that TLR2 and TLR4 expression in monocytes from $\mathrm{BD}$ patients was constitutively increased; however, this finding was not observed in neutrophils from these patients.

A recent GWAS with 2,461 BD cases and 2,458 healthy controls showed protective TLR4 and NOD2 polymorphisms, respectively associated with decreased response to lipopolysaccharide and muramyl dipeptide (40). Furthermore, a multicenter study with Chinese and Dutch patients has provided evidence that polymorphisms in TLR2 are involved in ocular BD susceptibility (41). A SNP of TIRAP, a MyD88adapter-like molecule with a regulatory role in TLR2 and TLR4 signaling, has been associated with BD in a British cohort (42), but results were not replicated in Middle-Eastern, Turkish or Italian patients (43).

Taken together, these findings implicate innate immunity and bacterial sensing mechanisms as important players in $\mathrm{BD}$ pathogenesis, with participation of diverse gene polymorphisms according to different ethnicities, and represent a promising investigational area in $\mathrm{BD}$.

\section{THE NF-אB PATHWAY}

Downstream signaling leading to internalization of the two nuclear factor $\kappa B$ subunits (p50 and p65) represents the canonical signal transduction pathway after activation of several PRR. Despite the inflammatory characteristics of BD suggesting NF- $\kappa B$ hyperactivation in BD patients (44), there are few studies in the area, but this has progressively been changing lately.

Polymorphisms in NFKB1 promoter (-94 insertion/deletion ATTG) (45) and NFKBIA (rs696) (46) were demonstrated to enhance the risk for $\mathrm{BD}$ in the Turkish population. It seems that NF- $\kappa \mathrm{B}$ plays a pivotal role in controlling T cells apoptosis in BD.
Although CD95 is highly expressed on T cells from BD patients, Todaro et al. (47) demonstrated decreased sensitivity to CD95induced apoptosis, possibly attributed to the inhibitory action of anti-apoptotic genes (CFLAR, BCL2L1, BCL2, CASP3, CASP8) and up-regulated expression of $I \kappa \kappa, I \kappa B$, and $N F-\kappa B$. Interestingly, thalidomide, a therapeutic agent used in severe mucocutaneous manifestations of $\mathrm{BD}$, and $\mathrm{NF}-\kappa \mathrm{B}$ small interfering RNA down-regulated cFLIP and Bcl-xL expression levels, ultimately increasing activated T cells sensitivity to CD95induced apoptosis in BD.

Constitutive NF- $\mathrm{KB}$ canonical pathway hyperactivation in $\mathrm{BD}$ phagocytes was previously reported by our group, as indicated by the over-expression of phosphorylated p65 subunit (44). Similarly, a monogenic form of an autoinflammatory disorder resembling $\mathrm{BD}$ was described in five families carrying heterozygous germline mutations of TNFAIP3, a potent inhibitor of the NF- $\kappa B$ canonical pathway (48). The mutant TNFAIP3-derived transcript A20 is not capable of modulating intracellular signaling, ultimately culminating in phagocyte hyperactivation and increased NF- $\kappa \mathrm{B}-$ mediated proinflammatory cytokines secretion. Moreover, carriers of NFKB1 variants have been reported to present a monogenic $\mathrm{BD}$-like disease, characterized by pathergy-like lesions and striking macrophage inflammasome activation. Finally, an autosomaldominant mucocutaneous ulceration disorder was recently associated with RELA mutations, encoding the NF- $\mathrm{BB}$ subunit p65 (49).

Previous studies further support the clinical overlap between BD and other autoinflammatory diseases with shared etiopathogenesis, such as familial Mediterranean fever $(4,50)$. MEFV M694V mutation frequency is increased in Turkish BD patients (40). Rare genetic variants of undetermined significance in inflammasome components upstream of NF- $\kappa \mathrm{B}$ have also been found in BD patients, especially NOD2 and NLRP3 (51-53). Some of these variants may contribute to the disease onset, but others could be only single nucleotide polymorphisms without any effect. Anyhow, inflammasome-activated NF- $\kappa \beta$ pathway dysregulation seems to be a common finding in disorders with BD-like phenotypes (54).

\section{ENDOTHELIAL CELL DYSFUNCTION}

As a pro-thrombotic condition, one would expect the existence of some sort of endothelial dysfunction in BD. A study in Turkish patients showed that patients with active disease presented lower nitric oxide serum levels than those in remission (55). Since endothelial cells are major producers of nitric oxide, the authors suggested a putative dysfunction in these cells. This would be probably mediated by increase in oxidative stress due to augmented malondialdehyde (a metabolite of polyunsaturated lipids oxidation by reactive oxygen species ROS) serum levels in active BD patients.

Fadini et al. (56) originally demonstrated a progressive decrease of circulating endothelial progenitor cells in BD patients, which might represent a vascular damage mechanism, since these cells are involved in vascular homeostasis and repair. 
The authors also showed a positive correlation between the number of endothelial progenitor cells and both BD activity score and C-reactive protein.

A systematic review aimed to evaluate subclinical atherosclerosis in $\mathrm{BD}$ by endothelial-mediated dilatation and by measurement of intima media thickness (IMT) of carotid arteries (57). Among nine studies, endothelial-mediated dilation was demonstrated to be impaired in $\mathrm{BD}$ even in inactive state. IMT was greater in $\mathrm{BD}$ patients, despite considerable variation that reflects the clinical heterogeneity of the disease.

\section{NEUTROPHIL HYPERACTIVITY}

Clinical and pathological data strongly suggest that neutrophil hyperactivity is a prominent feature in $\mathrm{BD}$ pathogenesis. Exacerbated neutrophil activity can be determined by evaluating oxidative burst, phagocytic and microbicide activities, activation of intracellular signaling pathway, among others. Takeno et al. (58) showed that ROS production is increased not only in BD patients but also in asymptomatic $H L A-B^{\star} 51$ carriers and even in transgenic mice expressing HLA$B^{\star} 51$. These observations suggest a mechanistic connection between the already known immunogenetic background of $\mathrm{BD}$ and its pathogenesis.

Carletto et al. (59) described that peripheral blood and skin (obtained by cutaneous abrasion) neutrophils from patients with active $\mathrm{BD}$ present higher migration capacity than those from healthy controls and $\mathrm{BD}$ patients with inactive disease. The increased migration capability was normalized when patients attained remission, suggesting that this mechanism is involved in the inflammatory state of the disease. In contrast, no significant abnormalities were observed in other neutrophil functions, such as adhesion or superoxide production after zymosan, phorbolmyristate-acetate (PMA) or N-formylmethionine-leucylphenylalanine (fMLP) stimuli. However, Yoshida et al. (60), using a chemoluminescence method to determine the superoxide production in $20 \mathrm{BD}$ patients and healthy controls, demonstrated a significantly higher superoxide production by neutrophils from BD patients after the same stimuli used by Carletto et al. (59).

Eksioglu-Demiralp et al. (61) studied the oxidative burst after stimuli with PMA or fMLP and the phagocytic activity against $E$. coli in neutrophils from healthy controls, BD patients ( $H L A-B^{\star} 51$ carriers or not), septic patients and patients with inflammatory arthropathy (namely, rheumatoid arthritis and ankylosing spondylitis). Oxidative burst was decreased in stimulated neutrophils from $\mathrm{BD}$ and septic patients, suggesting that phagocytes were exhausted and hypo-responsive in vitro due to previous in vivo hyper-activation. Interestingly, phagocytic activity was significantly increased in septic and inflammatory arthropathy groups, but did not differ between $\mathrm{BD}$ patients and healthy controls.

The same Turkish group published in 2002 another study reassessing phagocytic activity and oxidative burst profile after PMA stimulus of neutrophils from healthy controls, BD patients and "inflammatory patients" (septic, primary vasculitis, systemic lupus erythematous, osteomyelitis and pneumonia) (62).
Exclusively BD patients presented a decreased oxidative burst after stimulus, which was inhibited by nitric oxide synthase inhibitors, although significantly less than the healthy controls. There was no difference in phagocytic activity among the groups. Once again, the authors attributed the results to a possible in vivo pre-activated/exhaustion state of BD neutrophils.

Altogether, these data support the concept that neutrophils play a pivotal role in $\mathrm{BD}$ pathogenesis. However, there might be other factors contributing to $\mathrm{BD}$ development, many of them still unknown. It is unclear, for example, if the striking neutrophil hyperactivation occurs constitutively or if it is secondary to a yet unknown stimulus, such as bacterial (e.g.: Streptococcus) or viral infections. Therefore, in an attempt to clarify this doubtful issue, our group designed a study aiming to assess the classical phagocyte functions (i.e., oxidative burst, in vitro cytokine production, phagocytic and microbicide activities) before and after stimulus with pathogens and several microbial components in 30 healthy controls, 25 septic patients, 31 inactive, and 30 active BD patients (63). We observed that phagocytes from BD patients with severe manifestations exhibit significantly higher oxidative burst activity, both before and after PMA stimulation, compared to cells from patients with mild BD manifestations. Furthermore, we found significant positive correlations between BD patients' scores on the simplified Behçet's Disease Current Activity Form (BR-BDCAF), a validated tool to measure disease activity, and Streptococcus sanguinis-stimulated production of IL-23 by peripheral blood mononuclear cells (PBMC) and IL- 8 by neutrophils. In addition, significant positive correlations were also found between BRBDCAF score and constitutive production of TNF $\alpha$, IFN $\gamma$, IL-6, and IL-23 by PBMC. Thus, our study corroborates the participation of phagocyte in $\mathrm{BD}$ pathogenesis by the evidence that patients with severe BD exhibit phagocytic dysfunction and some extent of constitutive activation.

In contrast, an important aspect of neutrophil biology has largely been ignored despite the striking body of evidence of involvement of these cells in BD: neutrophil extracellular traps (NET) release. Our group originally showed an increased constitutive NET release in BD patients (64). Interestingly, NETosis was markedly stimulated by soluble CD40L, especially from plasma of active BD patients. Similarly, Le Joncour et al. (65) recently demonstrated that circulating NET components are elevated in active BD patients, mainly in those with vascular involvement, suggesting that NET may represent a potential therapeutic target for $\mathrm{BD}$-associated thrombotic risk.

Despite some controversy in the literature regarding neutrophil dysfunction in BD (summarized in Table 1), the bulk of evidence suggests that the activated status of phagocytes in $\mathrm{BD}$ is not a constitutive feature, but rather restricted to a fraction of severely active patients, and probably secondary to an unknown soluble factor (Figure 1).

\section{ROLE OF MONOCYTES IN BD}

Like neutrophils, monocytes are important agents of the innate immune system by means of their phagocytic activity, oxidative 
TABLE 1 | Controversies regarding phagocyte activity in Behçet's disease (BD).

\begin{tabular}{|c|c|c|c|}
\hline Author & Year & Brief description & Reference \\
\hline Takeno et al & 1995 & Increased oxidative burst in BD patients and HLA-B51 healthy controls. & $(58)$ \\
\hline Sahin S et al & 1996 & Increased adhesion. & (66) \\
\hline Carletto A et al & 1997 & Increased migration (active BD only). No difference regarding oxidative burst. & (59) \\
\hline Yoshida et al & 1998 & $\begin{array}{l}\text { Constitutively increased oxidative burst in BD neutrophils. Increased oxidative burst in neutrophils from healthy controls after } \\
\text { pretreatment with serum from BD patients. }\end{array}$ & (60) \\
\hline $\begin{array}{l}\text { Eksioglu- } \\
\text { Demiralp E et al }\end{array}$ & 2001 & Decreased oxidative burst. No difference regarding phagocytic activity compared to healthy controls. & $(61)$ \\
\hline Atalay $\mathrm{G}$ et al & 2002 & Decreased oxidative burst (active BD only). No difference regarding phagocytic activity. & (62) \\
\hline Neves et al & 2009 & $\begin{array}{l}\text { Both normal and BD neutrophils increased chemotactic capacity after incubation with BD plasma. No difference regarding } \\
\text { chemotaxis. }\end{array}$ & (38) \\
\hline Perazzio et al & 2015 & $\begin{array}{l}\text { Increased oxidative burst (severe BD only). Positive correlation between activity score and constitutive or Streptococcus } \\
\text { sanguinis-stimulated production of cytokines in vitro. No differences regarding phagocytic and microbicide activities. }\end{array}$ & (44) \\
\hline Perazzio et al & 2017 & $\begin{array}{l}\text { Plasma from BD patients exerted a stimulus on neutrophil extracellular traps release and oxidative burst, probably induced by } \\
\text { sCD } 40 \mathrm{~L}\end{array}$ & (44) \\
\hline Le Joncour et al & 2019 & Circulating neutrophil extracellular traps markers are elevated in BD and contribute to the procoagulant state & (65) \\
\hline
\end{tabular}

GENETICFACTORS

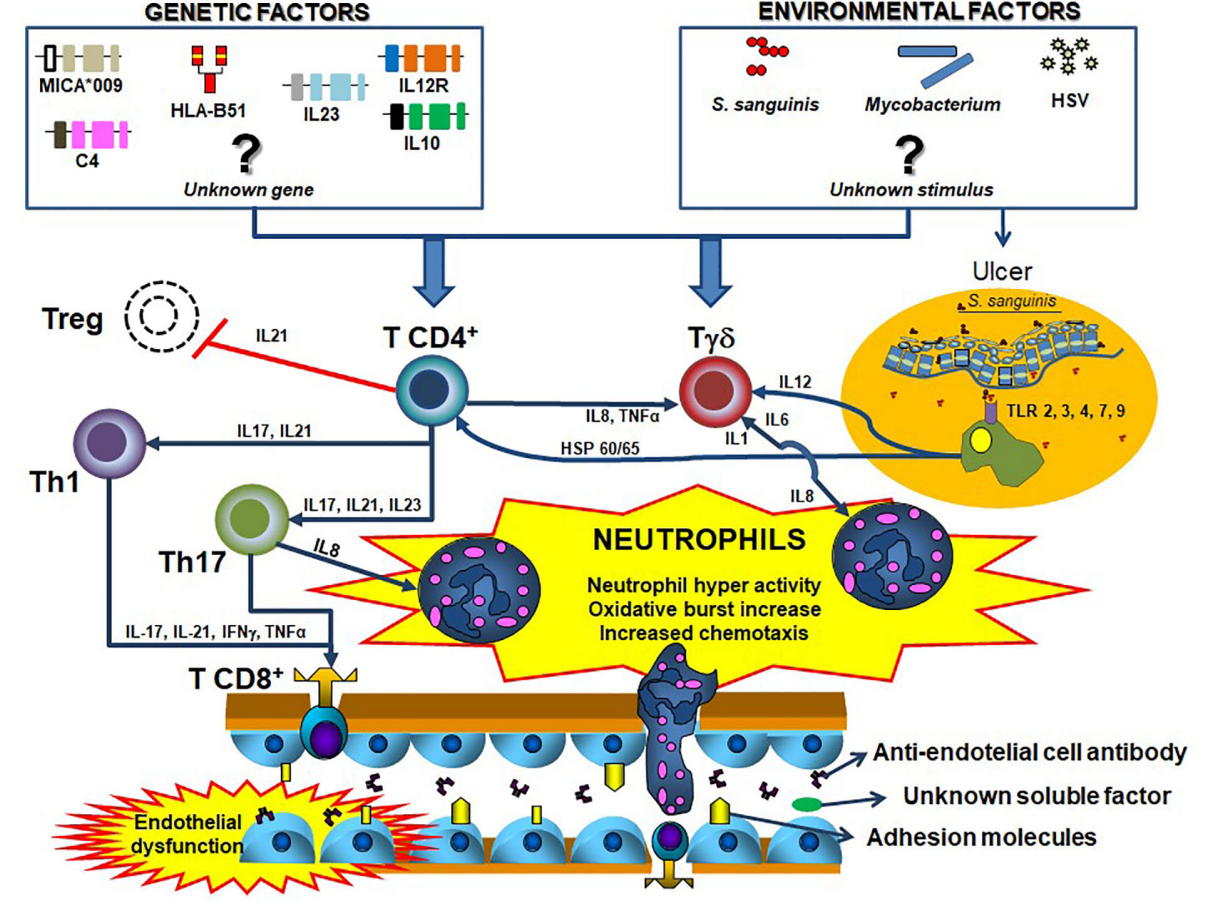

FIGURE 1 | Summary of the possible Behçet's disease pathogenesis. Distinct T helper cells mainly Th1 and Th17 have the ability of stimulating T effectors and T regulatory cells especially by the action of cytokines. Although some remain unknown, several genetic (e.g.: HLA-B*51, MICA, C4 copy number variation, among others),,, and environmental factors (e.g., Streptococcus sanguinis, Herpes-simplex virus, mycobacteria, among others) are involved in the process, by facilitating the activation of T cells. Similarly, the antigen presenting cells, especially macrophages from mucosa, stimulate immune cells by Toll-like receptors activation. All these innate and adaptive immune pathways culminate with the sequential neutrophil activation, considered the most important element in BD pathogenesis. blue closed arrows represent stimulation of a cell subtype mediated by cytokines, while red open lists represent inhibition.

burst and cytokine production. Thus, it is reasonable to suppose that their function and response to stimuli may bear some similarity to those of neutrophils, especially in diseases with neutrophil hyperactivity.

Indeed, Gogus et al. (67) showed that monocytes from BD and familial Mediterranean fever patients present higher oxidative burst activity than those from rheumatoid arthritis patients and healthy controls, especially when stimulated by sodium monourate crystals. Moreover, interactions between neutrophils and monocytes have received particular attention. For example, peptides released from activated human neutrophils stimulate monocyte adhesion and transmigration as well as macrophage oxidative burst (68).

Interestingly, monocytes from $\mathrm{BD}$ patients present higher expression of TLR2. Moreover, bacterial-derived lipoteichoic acid activated TLR2 increases neutrophil chemotaxis and 
adhesion to endothelial cells (38). Furthermore, active DB is associated with higher expressions of TLR2 and TLR4 in monocytes, as well as with a higher frequency of proinflammatory $\mathrm{CD} 14^{+} \mathrm{CD} 16^{+}$monocytes in the peripheral blood compared to healthy controls (39). In vitro lipopolysaccharidestimulated monocytes from BD patients produced similar amounts of TNF $\alpha$ compared to healthy controls cells; however, a higher in vitro production of TNF $\alpha$ was observed in monocytes from clinically active $\mathrm{BD}$ patients in comparison to those from quiescent BD patients (69). It would be intriguing to further explore this aspect in BD since monocytes seem to play a role in its pathogenesis as these cells may contribute to neutrophil activation after bacterial triggers in $\mathrm{BD}$ patients.

\section{SOLUBLE FACTORS AND AUTOANTIBODIES}

Cytokines and soluble receptors are major effectors of innate immunity and some of them have already been associated with BD pathogenesis. A previous study showed an increased expression of Th1 cytokines (IL-12, IL-18, and IFN $\gamma$ ) in skin and oral ulcers from active BD patients (70). In fact, Yanaginori et al. (71) demonstrated that stimulation with Streptococcal antigens specifically increased gene and protein expression of IL12p40, in conjunction with IL12p70 induction, in PBMC from $\mathrm{BD}$ patients. This finding provides evidence for Th1-skewed anti-bacterial host response mediated by IL-12 in BD patients. Two studies showed that serum and cerebrospinal fluid (CSF) levels of IL-15 and IL-18, two crucial Th1 cytokines, were increased in neuro-Behçet patients $(72,73)$.

Moreover, in the strict context of innate immunity, some studies showed that serum levels of IL-8, a potent neutrophil activator and chemotactic factor, are increased in BD patients $(66,74)$, especially in active disease (75). IL-8 levels were also elevated in synovial fluid from BD compared to osteoarthritis patients, which suggests an important role for this cytokine in $\mathrm{BD}$ pathogenesis (76). Inflammasome or NF- $\kappa \mathrm{B}$-derived IL-1 $\beta$, TNF $\alpha$, and IL- 6 are also representatives of strictly innate immunity soluble mediators and act individually or altogether in systemic inflammation, inducing acute phase reactants and phagocyte activation. These cytokines may play pivotal role on $\mathrm{BD}$ etiopathogenesis, as therapeutical blockade is indicated by current clinical guidelines (77). Among immunobiological therapies for $\mathrm{BD}$, certainly anti-TNF are the most frequently prescribed and are indicated for refractory mucocutaneous lesions, peripheral vascular symptoms (deep venous thrombosis and arterial aneurisms) and as alternative for parenchymal central nervous system and ocular manifestations. Anti-IL-6 therapy has been indicated on refractory central nervous system manifestations (78-80) and anti-IL-1 $\beta$ showed promising results for severe ocular $(81,82)$ and mucocutaneous clinical phenotype $(83,84)$.

Interestingly, Alpsoy et al. (85) demonstrated that IL8 gene expression was increased in macrophages from BD patients and healthy controls after incubation with serum from active $\mathrm{BD}$ patients. Similarly, (85) several other studies demonstrated the capacity of serum or plasma from BD patients to stimulate the innate immune system. Yoshida et al. primed neutrophils from healthy controls with BD serum and observed an increase in the production of superoxide similar to that observed after stimuli with zymosan, PMA or fMLP. (60). However, the absence of objective $\mathrm{BD}$ disease activity determination was a caveat of that study. Sahin et al. (66) demonstrated an increased adhesion ability of normal neutrophils to human umbilical vascular endothelial cells and increased expression of adhesion molecules (CD11a, CD18, and ICAM-1) when exposed to BD serum, compared to the stimulus of normal serum. However, the authors could not find any difference between serum from patients with active and inactive disease, possibly due to similarly high IL-8 serum levels in both groups. Another study from the same group showed that BD patients presented higher monocyte expression of CD14, a monocyte-activating marker, as well as higher soluble CD14 serum levels than healthy controls (86). Furthermore, the supernatant of BD monocyte culture significantly increased the adhesion ability of normal neutrophils to endothelial cells in vitro. These results indicate that BD monocytes are active and produce a milieu of pro inflammatory cytokines, which may play a role in the chronic inflammation of BD.

Neves et al. showed that chemotaxis was similar in neutrophils from $\mathrm{BD}$ and normal controls after stimulation with lipoteichoic acid (38). Interestingly, both healthy and BD neutrophils presented increased chemotactic capacity when incubated in the presence of $\mathrm{BD}$ plasma or stimulated with C5a, B4 leukotriene or fMLP. Similarly to Sahin et al. (86), CD14 expression in monocytes and soluble CD14 serum levels were increased in BD patients. Additionally, the authors showed a positive correlation between BDCAF and soluble CD14 serum levels, suggesting that the soluble proinflammatory factors produced in $\mathrm{BD}$ correlate with disease activity.

Our group also demonstrated that NET release and oxidative burst were stimulated with plasma from BD patients (64). In addition, markedly elevated sCD40L serum levels in conjunction with CD40L overexpression on $\mathrm{CD}^{+}{ }^{+} \mathrm{T}$ cells from $\mathrm{BD}$ patients were observed. Interestingly, we originally described that both NET release and oxidative burst were exacerbated by recombinant $s C D 40 \mathrm{~L}$ and decreased after sCD40L blockade, suggesting a possible role of this mediator on $\mathrm{BD}$ pathogenesis.

Serum and plasma seem not to be the only carriers of soluble factors related to phagocyte activation in $\mathrm{BD}$. Chemokine levels in aqueous humor are apparently also increased in $\mathrm{BD}$ patients with ocular manifestations. El-Asrar et al. (87) demonstrated that CXCL1 and CXCL10 were significantly higher in aqueous humor of patients with BD compared to patients with Vogt-KoyanagiHarada disease and $H L A-B^{\star} 27$-associated uveitis. Additionally, CCR5 and CXCR3 had increased expression in biopsy specimens of oral ulcers from BD patients compared to healthy controls (88), and MIP-1 $\beta$ (macrophage inflammatory protein $1 \beta$ ) had increased serum levels in BD (70), indicating a Th1-skewed immune response on $\mathrm{BD}$ immunopathology. Interestingly, another study showed increased expression of transmembrane 
CXCL16 on circulating plasmacytoid dendritic cells from BD patients, which might contribute to the high serum IFN- $\alpha$ levels seen in patients with BD (89).

Although $\mathrm{BD}$ is not a typical autoantibody-associated condition, anti- $\alpha$-enolase antibodies have been associated with the disease. One study demonstrated that Streptococcus sanguinis or BD serum stimuli increase $\alpha$-enolase expression on human microvascular endothelial dermal cells, a target for autoantibodies observed in a fraction of BD patients (90). Thus, hyper-expressed $\alpha$-enolase could react to anti- $\alpha$-enolase antibodies present in $\mathrm{BD}$ serum, eliciting immune response (91). Additionally, the same authors previously identified that heterogeneous nuclear ribonucleoprotein (hnRNP) A2/B1 is a cross-reactive target of anti- $\alpha$-enolase antibodies and that Streptococcus sanguinis or serum from active BD patients are capable of inducing in vitro expression of hnRNP A2/B1 in human microvascular endothelial dermal cells (92). Orem et al. (93) also described that plasma from BD patients impaired nitric oxide production by human umbilical vascular endothelial cells, suggesting an inhibitory effect over endothelial NO synthase.

Despite several pieces of evidence, the literature is still controversial regarding the potential role played by a possible soluble phagocyte- or endothelial-activating factor carried by serum or plasma (Figure 1). As discussed above, it is unclear whether phagocyte activation is constitutive in $\mathrm{BD}$ or secondary to a soluble factor stimulation. Additionally, even considering the existence of such a factor, the identity and the cells responsible for its production remain unknown. Therefore, this is an area of great interest and further research is warranted to clarify these questions.

\section{INNATE VERSUS ADAPTIVE IMMUNITY: A PARADIGM FROM THE PAST}

Although $\mathrm{BD}$ is considered an example of strong innate immunity activation, it is important to highlight that not all immune cells can be assigned strictly to either the innate or the adaptive arm of the immune system. The existence of bridge populations between the two classic arms of the immune system expands the paradigm of innate versus adaptive immunity and, thus, sheds doubt on the concept of "innate" versus "adaptive" immune-mediated diseases. The modern understanding of the immune system consists of an organizational continuum, rather than a dichotomic system, especially due to the acknowledgment of the bridge population subsets, which present functions comprehending the innate and adaptive poles (94). Macrophages, for example, can phagocyte and destroy microorganisms by the induction of oxidative burst, but bridges the gap between innate and adaptive immunity by processing and presenting antigens to lymphocytes. Other elements involved in the integration of innate and adaptive immunity include NKT cells, $\gamma \delta$ T cells, CD8 $\alpha$ T cells, and B1 cells. In addition, innate lymphoid cells also produce large amounts of cytokines attributed to adaptive immunity, such as IFN $\gamma$, IL- 4 and IL-17A.
This review refers mainly to the innate arm of the immune system in $\mathrm{BD}$. However, there are several pieces of evidence supporting the participation of the adaptive immunity in BD pathogenesis. Keller et al. (95) described a prominent $\mathrm{CD}^{+} \mathrm{CXCL}^{+} \mathrm{CCR}^{+} \mathrm{T}$ cell infiltrate in three different "neutrophilic" diseases: $\mathrm{BD}$, pustular psoriasis and generalized exanthematous pustulosis. Interestingly, these cells produced predominantly CXCL8 and GM-CSF, but not IL-5 and IFN $\gamma$. Therefore, it is possible that these cells constitute a different subset of $\mathrm{T}$ cells, since their phenotype and functions differ from those of other classical CD $4^{+}$cells, such as Th1, Th2, Th17, and are associated to a unique inflammation cascade that promotes neutrophil hyperactivation.

Additionally, Th1 cells producing TNF $\alpha$, IFN $\gamma$, IL-8, IL-12, CCR5, CXCR3, and MCP-1 (macrophage chemoattractant protein 1) were reported in several BD lesions, including oral and genital ulceration, pseudofolliculitis, pathergy pustules and bowel ulcers $(88,96)$. Data regarding regulatory T (Treg) cells are scarce and conflicting. Some studies demonstrated a high number of Treg cells $\left(\mathrm{CD} 4^{+} \mathrm{CD} 25^{\text {high }} \mathrm{Foxp} 3^{+}\right)$in peripheral blood and cerebrospinal fluid (CSF) from BD patients (97-99). On the other hand, one study reported a decreased frequency of Treg in peripheral blood (100) and another one showed no difference in Treg frequency between BD and healthy controls. However, BD patients presented a decreased frequency of activated Treg cells (CD45RA ${ }^{+}$CD $25^{+++}$) (101).

Th17 cells are also apparently important in $\mathrm{BD}$ pathogenesis, especially by recruiting neutrophils via G-CSF (102). Indeed, the percentage of peripheral Th17 cells and IL-17 production are increased in active BD (103). Noteworthy, $\mathrm{T} \gamma \delta$ and NKT cells are also capable of IL-17 production and apparently are associated with BD pathogenesis as well $(104,105)$. Geri et al. (101) demonstrated an increase in the number of Th17 cells and a reduction of Treg cells in the peripheral blood from BD patients, as well as increased serum levels of IL-21 compared to controls. In addition, healthy control $\mathrm{CD} 4^{+} \mathrm{T}$ cells stimulated in vitro with sera from active BD patients showed high IFN $\gamma$ and IL-17A and decreased $\mathrm{T}$ reg cells differentiation compared to stimulus with sera from BD patients in remission. Moreover, Bassyouni et al. (106) showed that Th17 polarization in BD patients is induced by high levels of the inflammatory mediator serum amyloid-A. Thus, IL-17 axis seems to coordinate interactions between lymphocytes and neutrophils in $\mathrm{BD}$ and may represent a potential therapeutic target. In fact, the adaptive immune system apparently can stimulate neutrophil functions, contributing to the hyper-activated status of these cells. Figure $\mathbf{1}$ summarizes a proposition for integrated pathogenesis of Behçet's disease.

\section{CONCLUSION}

Understanding Behçet's disease pathogenesis is a pivotal step for the development of novel and efficacious therapies. Nevertheless, polygenic inheritance with the participation of several unknown environmental factors contributes to heterogeneity among patients and extra challenge for elucidating its pathogenesis. 
Evidence indicates that innate immunity is prominently involved in $\mathrm{BD}$, which is illustrated by the striking neutrophil hyperactivity and its interaction with monocytes. However, adaptive immunity also seems to be important in $\mathrm{BD}$, with particular emphasis on Th1 and Th17 responses.

\section{Key messages}

1. Phagocyte hyperactivity, with increased oxidative burst and chemotaxis, is a hallmark of Behçet's disease.

2. Soluble factors carried in the plasma contribute to phagocyte dysfunction in BD

3. Innate and adaptive immunity play an important role in $\mathrm{BD}$ pathogenesis and the IL-17 axis seems to play a pivotal role in the integration of the two arms of the immune system in this disease.

\section{REFERENCES}

1. Zouboulis CC, Keitel WA. A historical review of early descriptions of Adamantiades-Behçet's disease. J Invest Dermatol (2002) 119(1):201-5. doi: 10.1046/j.1523-1747.2002.01798.x

2. Zouboulis CC. Benediktos Adamantiades and his forgotten contributions to medicine. Eur J Dermatol (2002) 12(5):471-4.

3. Cho SB, Cho S, Bang D. New insights in the clinical understanding of Behcet's disease. Yonsei Med J (2012) 53:35-42. doi: 10.3349/ ymj.2012.53.1.35

4. Kastner DL, Aksentijevich I, Goldbach-Mansky R. Autoinflammatory disease reloaded: a clinical perspective. Cell (2010) 140:784-90. doi: 10.1016/j.cell.2010.03.002

5. Ohno S, Ohguchi M, Hirose S, Matsuda H, Wakisaka A, Aizawa M. Close association of HLA-Bw51 with Behçet's disease. Arch Ophthalmol (1982) 100:1455-8. doi: 10.1001/archopht.1982.01030040433013

6. de Menthon M, Lavalley MP, Maldini C, Guillevin L, Mahr A. HLA-B51/B5 and the risk of Behçet's disease: a systematic review and meta-analysis of case-control genetic association studies. Arthritis Rheum (2009) 61:1287-96. doi: 10.1002/art.24642

7. Mizuki N, Meguro A, Ota M, Ohno S, Shiota T, Kawagoe T, et al. Genomewide association studies identify IL23R-IL12RB2 and IL10 as Behçet's disease susceptibility loci. Nat Genet (2010) 42:703-6. doi: 10.1038/ng.624

8. Remmers EF, Cosan F, Kirino Y, Ombrello MJ, Abaci N, Satorius C, et al. Genome-wide association study identifies variants in the MHC class I, IL10, and IL23R-IL12RB2 regions associated with Behçet's disease. Nat Genet (2010) 42:698-702. doi: 10.1038/ng.625

9. Kuranov AB, Kötter I, Henes JC, Abisheva ST, Steiert I, Riewerts F, et al. Behçet's disease in HLA-B ${ }^{\star} 51$ negative Germans and Turks shows association with HLABw4-80I. Arthritis Res Ther (2014) 16:R116. doi: 10.1186/ar4569

10. Hughes T, Coit P, Adler A, Yilmaz V, Aksu K, Duzgun N, et al. Identification of multiple independent susceptibility loci in the HLA region in Behcet's disease. Nat Genet (2013) 45:319-24. doi: 10.1038/ng.2551

11. Ombrello MJ, Kirino Y, de Bakker PI, Gül A, Kastner DL, Remmers EF. Behçet disease-associated MHC class I residues implicate antigen binding and regulation of cell-mediated cytotoxicity. Proc Natl Acad Sci USA (2014) 111:8867-72. doi: 10.1073/pnas.1406575111

12. Wu Z, Zheng W, Xu J, Sun F, Chen H, Li P, et al. IL10 polymorphisms associated with Behcet's disease in Chinese Han. Hum Immunol (2014) 75:271-6. doi: 10.1016/j.humimm.2013.11.009

13. Takeuchi M, Kastner DL, Remmers EF. The immunogenetics of Behçet's disease: A comprehensive review. J Autoimmun (2015) 64:137-48. doi: 10.1016/j.jaut.2015.08.013

14. Wu YL, Yang Y, Chung EK, Zhou B, Kitzmiller KJ, Savelli SL, et al. Phenotypes, genotypes and disease susceptibility associated with gene copy

\section{AUTHOR CONTRIBUTIONS}

SP conceived, reviewed the literature, designed, wrote, and reviewed the manuscript. LA reviewed and improved the manuscript. AS reviewed and improved the manuscript. All authors contributed to the article and approved the submitted version.

\section{FUNDING}

This study was supported by Fundação de Amparo à Pesquisa do Estado de São Paulo (FAPESP) n\# 2011/50292-2 and by Research and Development from Fleury Group n\# 12619. SP (grant \#233205/2014-4) and LA (grant \#310334/2019-5) are supported by the Brazilian research agency National Council for Research (CNPq).

number variations: complement $\mathrm{C} 4 \mathrm{CNV}$ s in European American healthy subjects and those with systemic lupus erythematosus. Cytogenet Genome Res (2008) 123:131-41. doi: 10.1159/000184700

15. Hou S, Qi J, Liao D, Zhang Q, Fang J, Zhou Y, et al. Copy number variations of complement component C4 are associated with Behcet's disease but not with ankylosing spondylitis associated with acute anterior uveitis. Arthritis Rheum (2013) 65:2963-70. doi: 10.1002/art.38116

16. Becker K, Fitzgerald O, Green AJ, Keogan M, Newbury-Ecob R, Greenhalgh $\mathrm{L}$, et al. Constitutional trisomy 8 and Behçet syndrome. Am J Med Genet A (2009) 149A:982-6. doi: 10.1002/ajmg.a.32756

17. Mora P, Avellis FO, Zavota L, Orsoni JG. Behçet's disease associated with trisomy 8 in a young Italian girl-a case report. Clin Exp Rheumatol (2008) 26:706.

18. Ripperger T, Tauscher M, Praulich I, Pabst B, Teigler-Schlegel A, Yeoh A, et al. Constitutional trisomy $8 \mathrm{p} 11.21 \mathrm{-q} 11.21$ mosaicism: a germline alteration predisposing to myeloid leukaemia. $\mathrm{Br}$ J Haematol (2011) 155:209-17. doi: 10.1111/j.1365-2141.2011.08817.x

19. Bernasconi P, Klersy C, Boni M, Cavigliano PM, Calatroni S, Giardini I, et al Incidence and prognostic significance of karyotype abnormalities in de novo primary myelodysplastic syndromes: a study on 331 patients from a single institution. Leukemia (2005) 19:1424-31. doi: 10.1038/sj.leu.2403806

20. Tada Y, Koarada S, Haruta Y, Mitamura M, Ohta A, Nagasawa K. The association of Behçet's disease with myelodysplastic syndrome in Japan: a review of the literature. Clin Exp Rheumatol (2006) 24:S115-9.

21. Esatoglu SN, Hatemi G, Salihoglu A, Hatemi I, Soysal T, Celik AF. A reappraisal of the association between Behçet's disease, myelodysplastic syndrome and the presence of trisomy 8: a systematic literature review. Clin Exp Rheumatol (2015) 33:S145-51.

22. Hayashi A, Nagafuchi H, Ito I, Hirota K, Yoshida M, Ozaki S. Lupus antibodies to the HMGB1 chromosomal protein: epitope mapping and association with disease activity. Mod Rheumatol (2009) 19:283-92. doi: 10.3109/s10165-009-0151-7

23. Maugeri N, Rovere-Querini P, Baldini M, Baldissera E, Sabbadini MG, Bianchi ME, et al. Oxidative stress elicits platelet/leukocyte inflammatory interactions via HMGB1: a candidate for microvessel injury in sytemic sclerosis. Antioxid Redox Signal (2014) 20:1060-74. doi: 10.1089/ars.2013.5298

24. Wibisono D, Csernok E, Lamprecht P, Holle JU, Gross WL, Moosig F. Serum HMGB1 levels are increased in active Wegener's granulomatosis and differentiate between active forms of ANCA-associated vasculitis. Ann Rheum Dis Engl (2010) 69:1888-9. doi: 10.1136/ard.2009.119172

25. de Souza A, Westra J, Bijzet J, Limburg PC, Stegeman CA, Bijl M, et al. Is serum HMGB1 a biomarker in ANCA-associated vasculitis? Arthritis Res Ther (2013) 15:R104. doi: 10.1186/ar4284

26. Shi Y, Sandoghchian Shotorbani S, Su Z, Liu Y, Tong J, Zheng D, et al Enhanced HMGB1 expression may contribute to Th17 cells activation in 
rheumatoid arthritis. Clin Dev Immunol (2012) 2012:295081. doi: 10.1155/ 2012/295081

27. Ahn JK, Cha HS, Bae EK, Lee J, Koh EM. Extracellular high-mobility group box 1 is increased in patients with Behcet's disease with intestinal involvement. J Korean Med Sci (2011) 26:697-700. doi: 10.3346/ jkms.2011.26.5.697

28. de Souza AWS, Perazzio SF, de Franca NR, Andrade LEC, Bijl M, Westra J, et al. High mobility group box 1 serum levels are increased in Behcet's disease, but not associated with disease activity or disease manifestations. Rheumatology (2015) 54:2151-5. doi: 10.1093/rheumatology/kev202

29. Han EC, Cho SB, Ahn KJ, Oh SH, Kim J, Kim DS, et al. Expression of Proinflammatory Protein S100A12 (EN-RAGE) in Behcet's Disease and Its Association with Disease Activity: A Pilot Study. Ann Dermatol (2011) 23:313-20. doi: 10.5021/ad.2011.23.3.313

30. Kibaroglu A, Eksioglu-Demiralp E, Akoglu T, Direskeneli H. T and NK cell subset changes with microbial extracts and human HSP60-derived peptides in Behçet's disease. Clin Exp Rheumatol (2004) 22:S59-63.

31. Hirohata S, Oka H, Mizushima Y. Streptococcal-related antigens stimulate production of IL6 and interferon-gamma by T cells from patients with Behcet's disease. Cell Immunol (1992) 140:410-9. doi: 10.1016/0008-8749 (92) $90207-6$

32. Direskeneli H. Behçet's disease: infectious aetiology, new autoantigens, and HLA-B51. Ann Rheum Dis (2001) 60:996-1002. doi: 10.1136/ard.60.11.996

33. Hatemi G, Bahar H, Uysal S, Mat C, Gogus F, Masatlioglu S, et al. The pustular skin lesions in Behcet's syndrome are not sterile. Ann Rheum Dis (2004) 63:1450-2. doi: 10.1136/ard.2003.017467

34. Tojo M, Zheng X, Yanagihori H, Oyama N, Takahashi K, Nakamura K, et al. Detection of herpes virus genomes in skin lesions from patients with Behçet's disease and other related inflammatory diseases. Acta Derm Venereol (2003) 83:124-7. doi: 10.1080/00015550310007472

35. Nomura Y, Kitteringham N, Shiba K, Goseki M, Kimura A, Mineshita S. Use of the highly sensitive PCR method to detect the Herpes simplex virus type 1 genome and its expression in samples from Behçet disease patients. J Med Dent Sci (1998) 45:51-8.

36. Hasan A, Fortune F, Wilson A, Warr K, Shinnick T, Mizushima Y, et al. Role of gamma delta $\mathrm{T}$ cells in pathogenesis and diagnosis of Behcet's disease. Lancet (1996) 347:789-94. doi: 10.1016/S0140-6736(96)90868-5

37. Yavuz S, Elbir Y, Tulunay A, Eksioglu-Demiralp E, Direskeneli H. Differential expression of toll-like receptor 6 on granulocytes and monocytes implicates the role of microorganisms in Behcet's disease etiopathogenesis. Rheumatol Int (2008) 28:401-6. doi: 10.1007/s00296007-0470-y

38. Neves FS, Carrasco S, Goldenstein-Schainberg C, Goncalves CR, de Mello SB. Neutrophil hyperchemotaxis in Behcet's disease: a possible role for monocytes orchestrating bacterial-induced innate immune responses. Clin Rheumatol (2009) 28:1403-10. doi: 10.1007/s10067-009-1261-5

39. Do JE, Kwon SY, Park S, Lee ES. Effects of vitamin D on expression of Tolllike receptors of monocytes from patients with Behcet's disease. Rheumatol (Oxford) (2008) 47:840-8. doi: 10.1093/rheumatology/ken109

40. Kirino Y, Zhou Q, Ishigatsubo Y, Mizuki N, Tugal-Tutkun I, Seyahi E, et al. Targeted resequencing implicates the familial Mediterranean fever gene MEFV and the toll-like receptor 4 gene TLR4 in Behcet disease. Proc Natl Acad Sci U.S.A. (2013) 110:8134-9. doi: 10.1073/pnas.1306352110

41. Fang J, Hu R, Hou S, Ye Z, Xiang Q, Qi J, et al. Association of TLR2 gene polymorphisms with ocular Behcet's disease in a Chinese Han population. Invest Ophthalmol Vis Sci (2013) 54:8384-92. doi: 10.1167/iovs.13-12878

42. Durrani O, Banahan K, Sheedy FJ, McBride L, Ben-Chetrit E, Greiner K, et al. TIRAP Ser180Leu polymorphism is associated with Behcet's disease. Rheumatol (Oxford) (2011) 50:1760-5. doi: 10.1093/rheumatology/ker200

43. Turunc G, Coskun D, Alibaz-Oner F, Coit P, Duzgun N, Alpsoy E, et al. TIRdomain-containing adaptor protein gene TIRAP S180L polymorphism is not increased in Behcet's disease patients in two ethnic cohorts. Clin Exp Rheumatol (2013) 31:54-6.

44. Perazzio SF, Soeiro Pereira PV, Souza AWS, Condino-Neto A, Andrade LEC. NF-kappa B Pathway Is Depleted In Phagocytes From Behcet's Disease Patients Secondarily To Constitutive Phosphorylation Of The p65 Subunit. Arthritis Rheum (2013) 65:S1114-S. doi: 10.1002/art.38216
45. Yalcin B, Atakan N, Alli N. The functional role of nuclear factor kappakappaB1 -94 ins/del ATTG promotor gene polymorphism in Behçet's disease: an exploratory study. Clin Exp Dermatol (2008) 33:629-33. doi: 10.1111/j.1365-2230.2008.02786.x

46. Yenmis G, Oner T, Cam C, Koc A, Kucuk OS, Yakicier MC, et al. Association of NFKB1 and NFKBIA polymorphisms in relation to susceptibility of Behçet's disease. Scand J Immunol (2015) 81:81-6. doi: $10.1111 /$ sji.12251

47. Todaro M, Zerilli M, Triolo G, Iovino F, Patti M, Accardo-Palumbo A, et al. NF-kappaB protects Behçet's disease T cells against CD95-induced apoptosis up-regulating antiapoptotic proteins. Arthritis Rheum (2005) 52:2179-91. doi: $10.1002 /$ art.21145

48. Zhou Q, Wang H, Schwartz DM, Stoffels M, Park YH, Zhang Y, et al. Lossof-function mutations in TNFAIP3 leading to A20 haploinsufficiency cause an early-onset autoinflammatory disease. Nat Genet (2016) 48:67-73. doi: $10.1038 /$ ng.3459

49. Badran YR, Dedeoglu F, Leyva Castillo JM, Bainter W, Ohsumi TK, Bousvaros A, et al. Human RELA haploinsufficiency results in autosomaldominant chronic mucocutaneous ulceration. J Exp Med (2017) 214:193747. doi: $10.1084 / \mathrm{jem} .20160724$

50. Livneh A, Aksentijevich I, Langevitz P, Torosyan Y, G-Shoham N, Shinar Y, et al. A single mutated MEFV allele in Israeli patients suffering from familial Mediterranean fever and Behçet's disease (FMF-BD). Eur J Hum Genet (2001) 9:191-6. doi: 10.1038/sj.ejhg.5200608

51. Padula MC, Leccese P, Lascaro N, Padula AA, Carbone T, Martelli G, et al. Identification of a de novo NLRP3 gene variation in an Italian Behçet syndrome patient. Int J Immunogenet (2019) 46:339-41. doi: 10.1111/ iji.12442

52. Burillo-Sanz S, Montes-Cano MA, García-Lozano JR, Olivas-Martínez I, Ortego-Centeno N, García-Hernández FJ, et al. Behçet's disease and genetic interactions between HLA-B ${ }^{\star} 51$ and variants in genes of autoinflammatory syndromes. Sci Rep (2019) 9:2777. doi: 10.1038/s41598-019-39113-5

53. Burillo-Sanz S, Montes-Cano MA, García-Lozano JR, Ortiz-Fernández L, Ortego-Centeno N, García-Hernández FJ, et al. Mutational profile of rare variants in inflammasome-related genes in Behçet disease: A Next Generation Sequencing approach. Sci Rep (2017) 7:8453. doi: 10.1038/ s41598-017-09164-7

54. Steiner A, Harapas CR, Masters SL, Davidson S. An Update on Autoinflammatory Diseases: Relopathies. Curr Rheumatol Rep (2018) 20:39. doi: 10.1007/s11926-018-0749-x

55. Onur E, Kabaroglu C, Inanir I, Var A, Guvenc Y, Gunay O, et al. Oxidative stress impairs endothelial nitric oxide levels in Behcets' disease. Cutan Ocul Toxicol (2011) 30:217-20. doi: 10.3109/15569527.2011.554480

56. Fadini GP, Tognon S, Rodriguez L, Boscaro E, Baesso I, Avogaro A, et al. Low levels of endothelial progenitor cells correlate with disease duration and activity in patients with Behcet's disease. Clin Exp Rheumatol (2009) 27:814-21.

57. Merashli M, Ster IC, Ames PR. Subclinical atherosclerosis in Behcet's disease: A systematic review and meta-analysis. Semin Arthritis Rheum (2016) 45:502-10. doi: 10.1016/j.semarthrit.2015.06.018

58. Takeno M, Kariyone A, Yamashita N, Takiguchi M, Mizushima Y, Kaneoka $\mathrm{H}$, et al. Excessive function of peripheral blood neutrophils from patients with Behcet's disease and from HLA-B51 transgenic mice. Arthritis Rheum (1995) 38:426-33. doi: 10.1002/art.1780380321

59. Carletto A, Pacor ML, Biasi D, Caramaschi P, Zeminian S, Bellavite P, et al. Changes of neutrophil migration without modification of in vitro metabolism and adhesion in Behcet's disease. J Rheumatol (1997) 24:1332-6.

60. Yoshida T, Tanaka M, Sotomatsu A, Okamoto K, Hirai S. Serum of Behcet's disease enhances superoxide production of normal neutrophils. Free Radic Res (1998) 28:39-44. doi: 10.3109/10715769809097874

61. Eksioglu-Demiralp E, Direskeneli H, Kibaroglu A, Yavuz S, Ergun T, Akoglu T. Neutrophil activation in Behcet's disease. Clin Exp Rheumatol (2001) 19: S19-24.

62. Atalay G, Eksioglu-Demiralp E, Akoglu T, Direskeneli H. The effects of nitric oxide donors and inhibitors on neutrophil functions in Behcet's disease. Clin Exp Rheumatol (2002) 20:S17-20. 
63. Perazzio SF, Soeiro-Pereira PV, de Souza AW, Condino-Neto A, Andrade LE. Behçet's disease heterogeneity: cytokine production and oxidative burst of phagocytes are altered in patients with severe manifestations. Clin Exp Rheumatol (2015) 33:S85-95.

64. Perazzio SF, Soeiro-Pereira PV, dos Santos VC, de Brito MV, Salu B, Oliva MLV, et al. Soluble CD40L is associated with increased oxidative burst and neutrophil extracellular trap release in Behcet's disease. Arthritis Res Ther (2017) 19:15. doi: 10.1186/s13075-017-1443-5

65. Le Joncour A, Martos R, Loyau S, Lelay N, Dossier A, Cazes A, et al. Critical role of neutrophil extracellular traps (NETs) in patients with Behcet's disease. Ann Rheum Dis (2019) 78:1274-82. doi: 10.1136/annrheumdis2018-214335

66. Sahin S, Akoglu T, Direskeneli H, Sen LS, Lawrence R. Neutrophil adhesion to endothelial cells and factors affecting adhesion in patients with Behcet's disease. Ann Rheum Dis (1996) 55:128-33. doi: 10.1136/ard.55.2.128

67. Gogus F, Fresko I, Elbir Y, Eksioglu-Demiralp E, Direskeneli H. Oxidative burst response to monosodium urate crystals in patients with Behcet's syndrome. Clin Exp Rheumatol (2005) 23:S81-5.

68. Quinn KL, Henriques M, Tabuchi A, Han B, Yang H, Cheng WE, et al. Human neutrophil peptides mediate endothelial-monocyte interaction, foam cell formation, and platelet activation. Arterioscler Thromb Vasc Biol (2011) 31:2070-9. doi: 10.1161/ATVBAHA.111.227116

69. Slobodin G, Toukan Y, Rosner I, Rozenbaum M, Boulman N, Pavlotzky E, et al. LPS-stimulated production of TNF-alpha by peripheral blood monocytes in patients with Behcet's disease. Clin Rheumatol (2007) 26:764-7. doi: 10.1007/s10067-006-0371-6

70. Ben Ahmed M, Houman H, Miled M, Dellagi K, Louzir H. Involvement of chemokines and Th1 cytokines in the pathogenesis of mucocutaneous lesions of Behcet's disease. Arthritis Rheum (2004) 50:2291-5. doi: 10.1002/art.20334

71. Yanagihori H, Oyama N, Nakamura K, Mizuki N, Oguma K, Kaneko F. Role of IL-12B promoter polymorphism in Adamantiades-Behcet's disease susceptibility: An involvement of Th1 immunoreactivity against Streptococcus Sanguinis antigen. J Invest Dermatol (2006) 126:1534-40. doi: $10.1038 /$ sj.jid.5700203

72. Hamzaoui K, Hamzaoui A, Ghorbel I, Khanfir M, Houman H. Levels of IL15 in serum and cerebrospinal fluid of patients with Behcet's disease. Scand J Immunol (2006) 64:655-60. doi: 10.1111/j.1365-3083.2006.01844.x

73. Musabak U, Pay S, Erdem H, Simsek I, Pekel A, Dinc A, et al. Serum interleukin-18 levels in patients with Behcet's disease. Is its expression associated with disease activity or clinical presentations? Rheumatol Int (2006) 26:545-50. doi: 10.1007/s00296-005-0029-8

74. Durmazlar SP, Ulkar GB, Eskioglu F, Tatlican S, Mert A, Akgul A. Significance of serum interleukin-8 levels in patients with Behcet's disease: high levels may indicate vascular involvement. Int J Dermatol (2009) 48:25964. doi: 10.1111/j.1365-4632.2009.03905.x

75. Zouboulis CC, Katsantonis J, Ketteler R, Treudler R, Kaklamani E, Hornemann S, et al. Adamantiades-Behcet's disease: interleukin-8 is increased in serum of patients with active oral and neurological manifestations and is secreted by small vessel endothelial cells. Arch Dermatol Res (2000) 292:279-84. doi: 10.1007/s004030000128

76. Ertenli I, Kiraz S, Calguneri M, Celik I, Erman M, Haznedaroglu IC, et al. Synovial fluid cytokine levels in Behcet's disease. Clin Exp Rheumatol (2001) 19:S37-41.

77. Bettiol A, Hatemi G, Vannozzi L, Barilaro A, Prisco D, Emmi G. Treating the Different Phenotypes of Behçet's Syndrome. Front Immunol (2019) 10:2830:2830. doi: 10.3389/fimmu.2019.02830

78. Lopalco G, Fabiani C, Sota J, Lucherini OM, Tosi GM, Frediani B, et al. IL-6 blockade in the management of non-infectious uveitis. Clin Rheumatol (2017) 36:1459-69. doi: 10.1007/s10067-017-3672-z

79. Shapiro LS, Farrell J, Borhani Haghighi A. Tocilizumab treatment for neuroBehcet's disease, the first report. Clin Neurol Neurosurg (2012) 114:297-8. doi: 10.1016/j.clineuro.2011.10.024

80. Addimanda O, Pipitone N, Pazzola G, Salvarani C. Tocilizumab for severe refractory neuro-Behçet: three cases IL-6 blockade in neuro-Behçet. Semin Arthritis Rheum (2015) 44:472-5. doi: 10.1016/j.semarthrit.2014.08.004

81. Sota J, Rigante D, Lopalco G, Frediani B, Franceschini R, Galeazzi M, et al. Biological therapies for the treatment of Behçet's disease-related uveitis beyond TNF-alpha blockade: a narrative review. Rheumatol Int (2018) 38:25-35. doi: 10.1007/s00296-017-3775-5

82. Fabiani C, Sota J, Tosi GM, Franceschini R, Frediani B, Galeazzi M, et al. The emerging role of interleukin (IL)-1 in the pathogenesis and treatment of inflammatory and degenerative eye diseases. Clin Rheumatol (2017) 36:2307-18. doi: 10.1007/s10067-016-3527-z

83. Grayson PC, Yazici Y, Merideth M, Sen HN, Davis M, Novakovich E, et al. Treatment of mucocutaneous manifestations in Behçet's disease with anakinra: a pilot open-label study. Arthritis Res Ther (2017) 19:69. doi: 10.1186/s13075-017-1222-3

84. Emmi G, Talarico R, Lopalco G, Cimaz R, Cantini F, Viapiana O, et al. Efficacy and safety profile of anti-interleukin-1 treatment in Behçet's disease: a multicenter retrospective study. Clin Rheumatol (2016) 35:1281-6. doi: 10.1007/s10067-015-3004-0

85. Alpsoy E, Kodelja V, Goerdt S, Orfanos CE, Zouboulis Ch C. Serum of patients with Behcet's disease induces classical (pro-inflammatory) activation of human macrophages in vitro. Dermatology (2003) 206:22532. doi: $10.1159 / 000068888$

86. Sahin S, Lawrence R, Direskeneli H, Hamuryudan V, Yazici H, Akoglu T. Monocyte activity in Behcet's disease. Br J Rheumatol (1996) 35:424-9. doi: 10.1093/rheumatology/35.5.424

87. El-Asrar AM, Al-Obeidan SS, Kangave D, Geboes K, Opdenakker G, Van Damme J, et al. CXC chemokine expression profiles in aqueous humor of patients with different clinical entities of endogenous uveitis. Immunobiology (2011) 216:1004-9. doi: 10.1016/j.imbio.2011.03.007

88. Dalghous AM, Freysdottir J, Fortune F. Expression of cytokines, chemokines, and chemokine receptors in oral ulcers of patients with Behcet's disease (BD) and recurrent aphthous stomatitis is Th1-associated, although Th2-association is also observed in patients with BD. Scand J Rheumatol (2006) 35:472-5. doi: 10.1080/03009740600905380

89. Yilmaz S, Cinar M, Pekel A, Simsek I, Musabak U, Erdem H, et al. The expression of transmembrane and soluble CXCL16 and the relation with interferon-alpha secretion in patients with Behcet's disease. Clin Exp Rheumatol (2013) 31:84-7.

90. Cho S, Zheng Z, Cho SB, Choi MJ, Lee KH, Bang D. Streptococcus sanguinis and the sera of patients with Behcet's disease stimulate membrane expression of alpha-enolase in human dermal microvascular endothelial cells. Arch Dermatol Res (2013) 305:223-32. doi: 10.1007/s00403-012-1298-1

91. Lee KH, Chung HS, Kim HS, Oh SH, Ha MK, Baik JH, et al. Human alphaenolase from endothelial cells as a target antigen of anti-endothelial cell antibody in Behçet's disease. Arthritis Rheum (2003) 48:2025-35 doi: 10.1002/art.11074

92. Cho SB, Zheng Z, Cho S, Ahn KJ, Choi MJ, Kim DY, et al. Both the sera of patients with Behcet's disease and Streptococcus sanguis stimulate membrane expression of hnRNP A2/B1 in endothelial cells. Scand J Rheumatol (2013) 42:241-6. doi: 10.3109/03009742.2012.733728

93. Orem A, Erturk M, Cimsit G, Kural BV. Effect of plasma from patients with Behcet's disease on the production of nitric oxide in cultured human umbilical vein endothelial cells. Med Princ Pract (2004) 13:35-8. doi: 10.1159/000074049

94. Borghesi L, Milcarek C. Innate versus adaptive immunity: a paradigm past its prime? Cancer Res (2007) 67:3989-93. doi: 10.1158/0008-5472.CAN-070182

95. Keller M, Spanou Z, Schaerli P, Britschgi M, Yawalkar N, Seitz M, et al. T cell-regulated neutrophilic inflammation in autoinflammatory diseases. J Immunol (2005) 175:7678-86. doi: 10.4049/jimmunol.175.11.7678

96. Houman H, Hamzaoui A, Ben Ghorbal I, Khanfir M, Feki M, Hamzaoui K Abnormal expression of chemokine receptors in Behcet's disease: relationship to intracellular Th1/Th2 cytokines and to clinical manifestations. J Autoimmun (2004) 23:267-73. doi: 10.1016/j.jaut.2004. 07.005

97. Hamzaoui K, Borhani Haghighi A, Ghorbel IB, Houman H. RORC and Foxp3 axis in cerebrospinal fluid of patients with neuro-Behcet's disease. J Neuroimmunol (2011) 233:249-53. doi: 10.1016/j.jneuroim.2011.01.012

98. Pekiner FN, Aytugar E, Demirel GY, Borahan MO. Interleukin-2, interleukin-6 and T regulatory cells in peripheral blood of patients with Behcet's disease and recurrent aphthous ulcerations. J Oral Pathol Med (2012) 41:73-9. doi: 10.1111/j.1600-0714.2011.01061.x 
99. Hamzaoui K, Hamzaoui A, Houman H. CD4+CD25+ regulatory T cells in patients with Behcet's disease. Clin Exp Rheumatol (2006) 24:S71-8.

100. Nanke Y, Kotake S, Goto M, Ujihara H, Matsubara M, Kamatani N. Decreased percentages of regulatory $\mathrm{T}$ cells in peripheral blood of patients with Behcet's disease before ocular attack: a possible predictive marker of ocular attack. Mod Rheumatol (2008) 18:354-8. doi: 10.3109/s10165-008-0064-x

101. Geri G, Terrier B, Rosenzwajg M, Wechsler B, Touzot M, Seilhean D, et al. Critical role of IL-21 in modulating TH17 and regulatory T cells in Behcet disease. J Allergy Clin Immunol (2011) 128:655-64. doi: 10.1016/ j.jaci.2011.05.029

102. Mills KH. Induction, function and regulation of IL-17-producing T cells. Eur J Immunol (2008) 38:2636-49. doi: 10.1002/eji.200838535

103. Hamzaoui K, Bouali E, Ghorbel I, Khanfir M, Houman H, Hamzaoui A. Expression of Th-17 and RORgammat mRNA in Behcet's Disease. Med Sci Monit (2011) 17:Cr227-34. doi: 10.12659/MSM.881720

104. Yamaguchi Y, Takahashi H, Satoh T, Okazaki Y, Mizuki N, Takahashi K, et al. Natural killer cells control a T-helper 1 response in patients with Behcet's disease. Arthritis Res Ther (2010) 12:R80. doi: 10.1186/ar3005
105. Nishida T, Hirayama K, Nakamura S, Ohno S. Proliferative response of $\mathrm{CD} 8+$ gamma delta+ $\mathrm{T}$ cells to Streptococcus sanguis in patients with Behcet's disease. Ocul Immunol Inflammation (1998) 6:139-44. doi: 10.1076/ ocii.6.3.139.4035

106. Bassyouni IH, Mohammed WHS, Taha FM, El Refai RM. Clinical significance of CCN2/connective tissue growth factor in Behçet's disease patients. Int J Rheum Dis (2019) 22:1459-65. doi: 10.1111/1756-185X.13597

Conflict of Interest: The authors declare that the research was conducted in the absence of any commercial or financial relationships that could be construed as a potential conflict of interest.

Copyright (C) 2020 Perazzio, Andrade and de Souza. This is an open-access article distributed under the terms of the Creative Commons Attribution License (CC BY). The use, distribution or reproduction in other forums is permitted, provided the original author(s) and the copyright owner(s) are credited and that the original publication in this journal is cited, in accordance with accepted academic practice. No use, distribution or reproduction is permitted which does not comply with these terms. 